\title{
Electrodeposition of dicalcium phosphate dihydrate coatings on stainless steel substrates
}

\author{
BELAVALLI E PRASAD and P VISHNU KAMATH* \\ Department of Chemistry, Central College, Bangalore University, Bangalore 560 001, India
}

MS received 23 February 2012

\begin{abstract}
Cathodic reduction of an aqueous solution containing dissolved calcium and phosphate ions results in the deposition of micrometer thick $\mathrm{CaHPO}_{4} \cdot 2 \mathrm{H}_{2} \mathrm{O}$ (dicalcium phosphate dihydrate) coatings on stainless steel substrates. The coating obtained at a low deposition current $\left(8 \mathrm{~mA} \mathrm{~cm}{ }^{-2}\right)$ comprises lath-like crystallites oriented along 020. The 020 crystal planes are non-polar and have a low surface energy. At a high deposition current $\left(12 \mathrm{~mA} \mathrm{~cm}^{-2}\right)$, platelets oriented along $12 \overline{1}$ are deposited. $\mathrm{CaHPO}_{4} \cdot 2 \mathrm{H}_{2} \mathrm{O}$ is an important precursor to the nucleation of hydroxyapatite, the inorganic component of bones. Differently oriented $\mathrm{CaHPO}_{4} \cdot 2 \mathrm{H}_{2} \mathrm{O}$ coatings transform to hydroxyapatite with different kinetics, the transformation being more facile when the coating is oriented along $12 \overline{1}$. These observations have implications for the development of electrodeposited biocompatible coatings for metal endoprostheses for medical applications.
\end{abstract}

Keywords. Electrodeposition; orientation; DCPD; hydroxyapatite.

\section{Introduction}

Calcium phosphate crystallizes in various forms, such as dicalcium phosphate dihydrate $\left(\mathrm{CaHPO}_{4} \cdot 2 \mathrm{H}_{2} \mathrm{O}\right.$, DCPD), dicalcium phosphate anhydrous $\left(\mathrm{CaHPO}_{4}, \mathrm{DCPA}\right)$, tricalcium phosphate $\left(\mathrm{Ca}_{3}\left(\mathrm{PO}_{4}\right)_{2}, \mathrm{TCP}\right)$, octacalcium phosphate $\left(\mathrm{Ca}_{8}\left(\mathrm{HPO}_{4}\right)_{2}\left(\mathrm{PO}_{4}\right)_{4} \cdot 5 \mathrm{H}_{2} \mathrm{O}, \mathrm{OCP}\right)$, amorphous calcium phosphate $(\mathrm{ACP})$ and hydroxyapatite $\left(\mathrm{Ca}_{10}\left(\mathrm{PO}_{4}\right)_{6}(\mathrm{OH})_{2}, \mathrm{HA}\right)$. Among all calcium phosphate phases, hydroxyapatite is thermodynamically the most stable phase. The formation of different phases depends upon the $\mathrm{Ca} / \mathrm{P}$ molar ratio, $\mathrm{pH}$ and temperature of synthesis (Drissens et al 1994).

Calcium phosphate phases are important bioinorganic materials involved in the biomineralization of bones and teeth (Johnsson and Nancollas 1992). They are also used as tooth-filling cements (Yamashita and Kanazawa 1989) and as biocompatible coatings for metal endoprostheses (Huaxia et al 1992).

Among various calcium phosphates, DCPD is important for the following reasons: (i) DCPD is an acidic calcium phosphate and consequently has high solubility under physiological conditions. Thereby, it is an important precursor to the crystallization of hydroxyapatite, the inorganic component of the bone material (Constantz et al 1998), (ii) DCPD is also found in pathological calcification as in dental calculi, crystalluria and urinary stones (Legeros 1991, 1994; Hesse and Heimabch 1999), (iii) in therapeutics, DCPD is used in calcium phosphate cements (Yamamoto et al 1998) and as an intermediate for tooth remineralization (Chow

\footnotetext{
*Author for correspondence (vishnukamath8@ hotmail.com)
}

and Brown 1982) and (iv) DCPD also has technological applications as a flame retardant (Mostashari et al 2006).

DCPD crystallizes below $\mathrm{pH} 6.0$ with monoclinic symmetry (Dorozhkin 2007). The unit cell consists of alternating bilayers stacked along the $b$-crystallographic axis. One layer consists of calcium and hydrogenphosphate ions and the other layer contains water molecules. The calcium ions are octa-coordinated by six oxygen atoms of the anions and by two oxygen atoms of the water molecules (Curry and Jones 1971).

For biomedical applications, it is important to make calcium phosphate coatings on metal surfaces. Many techniques are reported in the literature for the fabrication of calcium phosphate coatings on metal surfaces, such as rf sputtering (Rukenstein et al 1983), chemical vapour deposition (Spoto et al 1994) and chemical spraying (Morancho et al 1983). These methods require prior synthesis of the desired material, high vacuum chamber, high power laser or electron beam source. They are cost and energy intensive and one may not get the desired composition in the coating.

Electrodeposition (Raemdonk et al 1984; Therese et al 1998) is a simple and low-temperature technique for the fabrication of coatings of diverse materials on metal surfaces. By using this method, it is possible to fabricate coatings on irregular objects, control the morphology and orientation by varying the deposition current, potential and bath composition.

In this paper, we report the electrodeposition of DCPD $\left(\mathrm{CaHPO}_{4} \cdot 2 \mathrm{H}_{2} \mathrm{O}\right)$ coatings on stainless steel substrates. A switch in the crystal orientation of the deposit was observed when the deposition current was changed. Differently oriented DCPD coatings were found to transform into hydroxyapatite 
with different kinetics. Based on the surface energies of different crystal faces of DCPD and the observed morphological changes, we suggest that the transformation occurs by a dissolution-reprecipitation mechanism.

\section{Experimental}

A diammonium hydrogenphosphate solution $(0.60 \mathrm{M}$, $50 \mathrm{~mL}$ ) was added to a standard $(1 \mathrm{M})$ calcium nitrate solution $(50 \mathrm{~mL})$. The white precipitate formed was dissolved using dilute nitric acid and the clear solution was diluted to obtain a stock solution of $0.2 \mathrm{M}$ in $\mathrm{Ca}^{2+}([\mathrm{Ca}] /[\mathrm{P}]=$ 1.67). The $\mathrm{pH}$ of the stock solution was $2 \cdot 4$. All the solutions were prepared using ion-exchanged type-I water (MilliQ Academic water purification system, specific resistance $18 \cdot 2$ megaohm $\mathrm{cm}$ ).

A stainless steel flag (area $4.5 \mathrm{~cm}^{2}$ ) was used as cathode and a Pt-mesh $\left(28 \mathrm{~cm}^{2}\right.$ geometric area) was used as the counter electrode. The depositions were carried out galvanostatically (current density, $8-12 \mathrm{~mA} \mathrm{~cm}{ }^{-2} ; t, 60 \mathrm{~min}$ ) using CHI Model 408A galvanostat/potentiostat. The deposition potentials were measured with respect to a saturated calomel electrode. During electrodeposition, temperature of the bath was maintained at $45{ }^{\circ} \mathrm{C}$ (IKA ETS-D5 Heater). After deposition, the coatings were rinsed with type-I water and dried at $65{ }^{\circ} \mathrm{C}$. Prior to electrodeposition, the working electrode was electrochemically polished as explained elsewhere (Corrigan and Bendert 1989). At least two coatings were prepared under each condition to verify the reproducibility of the observed effects.

$\mathrm{CaHPO}_{4} \cdot 2 \mathrm{H}_{2} \mathrm{O} \rightarrow$ hydroxyapatite transformation was carried out by ageing the as-deposited coatings in $2 \mathrm{M}$ sodium hydroxide at $60-85^{\circ} \mathrm{C}$ for $6-18 \mathrm{~h}$. After ageing, the coatings were rinsed with type-I water and dried at $65^{\circ} \mathrm{C}$.

All the coatings were characterized by $\mathrm{X}$-ray diffraction (XRD), by mounting the electrode directly on a Bruker aXS Model D8 advance powder X-ray diffractometer $(\mathrm{CuK} \alpha$ source, $\lambda=1.5418 \AA$ ). XRD profiles were fit by the Rietveld method (fullprof suite), using the published structure of $\mathrm{CaHPO}_{4} \cdot 2 \mathrm{H}_{2} \mathrm{O}$ (ICSD No. CC 16132) (I1a1, $a=5 \cdot 812 \AA$, $\left.b=15.180 \AA, c=6.239 \AA, \beta=116 \cdot 43^{\circ}\right)$. The quality of the fit was judged from the $R$ values and also by an examination of the difference profile. The observation of systematic residual intensities in the difference profile at positions corresponding to the different Bragg reflections is indicative of oriented crystallization. In such a case, the Rietveld refinement was repeated by the inclusion of March function parameters to account for orientation. The March function has two refinable parameters, $G_{1}$ and $G_{2} . G_{2}$ is of importance in the present context. $G_{2}=0$ corresponds to a fully-oriented coating, while $G_{2}=1$ to a coating without any preferred orientation.

IR spectra were recorded using a Bruker Alpha-T FTIR spectrometer (Diamond crystal ATR mode, resolution $4 \mathrm{~cm}^{-1}, 400-4000 \mathrm{~cm}^{-1}$ ). Surface morphologies were studied using a scanning electron microscope (JEOL Model
JSM 6490LV microscope, operating voltage $15 \mathrm{kV}$ ) by mounting the as-prepared coating on conducting carbon tape and sputter coating with Pt to improve the conductivity.

\section{Results and discussion}

On passing current in a bath containing calcium and hydrogenphosphate ions, a white calcium phosphate film is seen to form within $5 \mathrm{~min}$. While the bulk $\mathrm{pH}$ is controlled by acidification of the bath to suppress the chemical precipitation of calcium phosphate phases, the $\mathrm{pH}$ at the surface of the cathode is higher than the bulk pH (Tlili et al 2003) and is determined by the various electrochemical reactions taking place close to it. The high $\mathrm{pH}$ generally causes the deposition of metal hydroxide or oxide coatings on the cathode (Zhitomirsky et al 1995). However, in the presence of phosphate ions in the bath, metal phosphates are formed owing to their lower solubility than metal hydroxides (Dobos 1975).

The reactions that take place at the cathode during electrodeposition of $\mathrm{CaHPO}_{4} \cdot 2 \mathrm{H}_{2} \mathrm{O}$ are:

1. Electrogeneration of base by electrolysis of water and nitrate reduction

$$
\begin{aligned}
2 \mathrm{H}_{2} \mathrm{O}+2 e^{-} & \rightarrow 2 \mathrm{OH}^{-}+\mathrm{H}_{2}, \\
\mathrm{NO}_{3}^{-}+2 e^{-}+\mathrm{H}_{2} \mathrm{O} & \rightarrow 2 \mathrm{OH}^{-}+\mathrm{NO}_{2}^{-} .
\end{aligned}
$$

2. Phosphate ion speciation depending upon the $\mathrm{pH}$

$$
\mathrm{H}_{2} \mathrm{PO}_{4}^{-}+\mathrm{OH}^{-} \rightarrow \mathrm{HPO}_{4}^{2-}+\mathrm{H}_{2} \mathrm{O} \text {. }
$$

3. Formation of $\mathrm{CaHPO}_{4} \cdot 2 \mathrm{H}_{2} \mathrm{O}$

$$
\mathrm{Ca}^{2+}+\mathrm{HPO}_{4}^{2-}+2 \mathrm{H}_{2} \mathrm{O} \rightarrow \mathrm{CaHPO}_{4} \cdot 2 \mathrm{H}_{2} \mathrm{O} \text {. }
$$

The different hydrogenphosphates are easily distinguished by their characteristic IR spectra, especially in the $\mathrm{OH}$ stretching region. There are four vibrations in the range $3600-3100 \mathrm{~cm}^{-1}$ (figure 1a), which show the presence of two kinds of water molecules. Lecomte and coworkers (1955) have assigned the high wavenumber peaks to bound water molecules and low wavenumber peaks to the free water molecules. On the other hand, Petrov et al (1967) have assigned the higher wavenumber peaks to loosely bound water and low wavenumber peaks to water molecules which are directly bonded to calcium atoms. The absorptions in the range $1250-500 \mathrm{~cm}^{-1}$ correspond to $\mathrm{HPO}_{4}^{2-}$.

$\mathrm{X}$-ray diffraction was used for identification of the electrodeposited solid. XRD pattern of the as-deposited coating obtained when the deposition current was $8 \mathrm{~mA} \mathrm{~cm}$ ch $^{-2}$ is shown in figure 2. Sharp Bragg reflections are observed at $d$-spacings corresponding to the DCPD phase as reported in JCPDS database (PDF: 72-0713). However, the observed relative intensities of the different reflections do not match with those reported. On performing a Rietveld fit of the observed profile, residual intensity was seen in the difference profile at $2 \theta$ value corresponding to the 020 plane. Such residual 


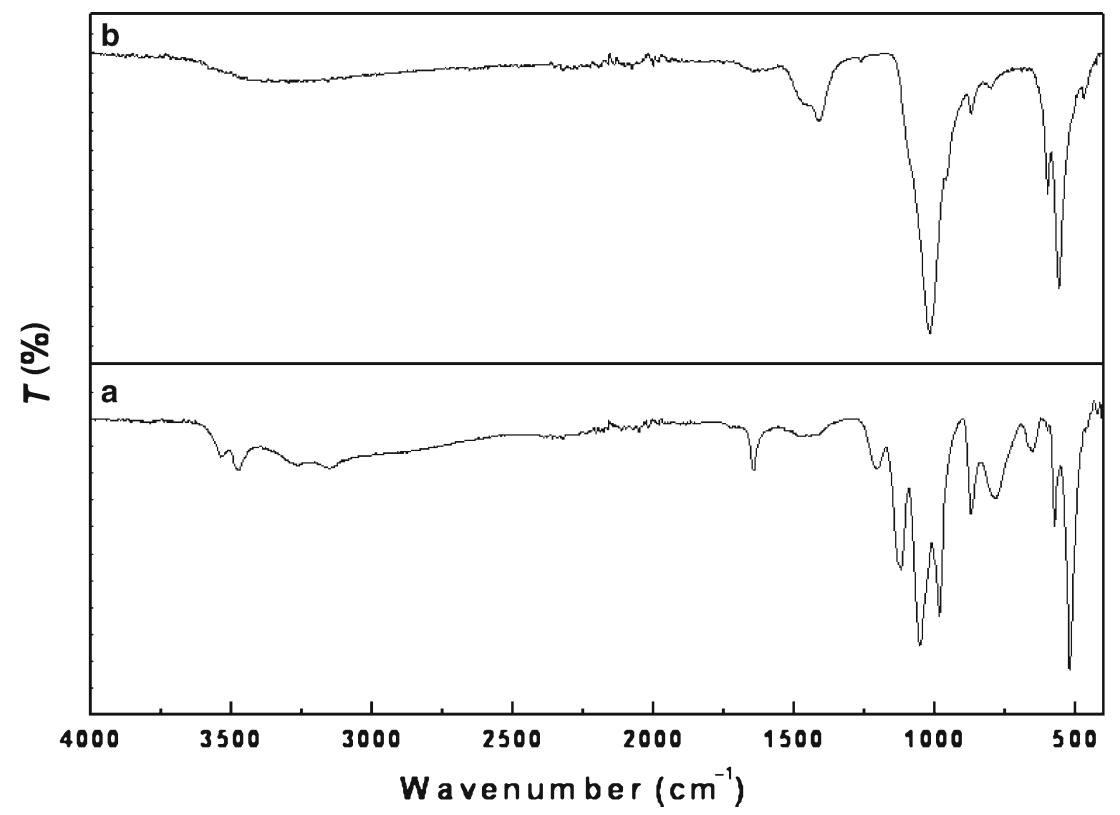

Figure 1. IR spectra of (a) DCPD and (b) hydroxyapatite coatings.

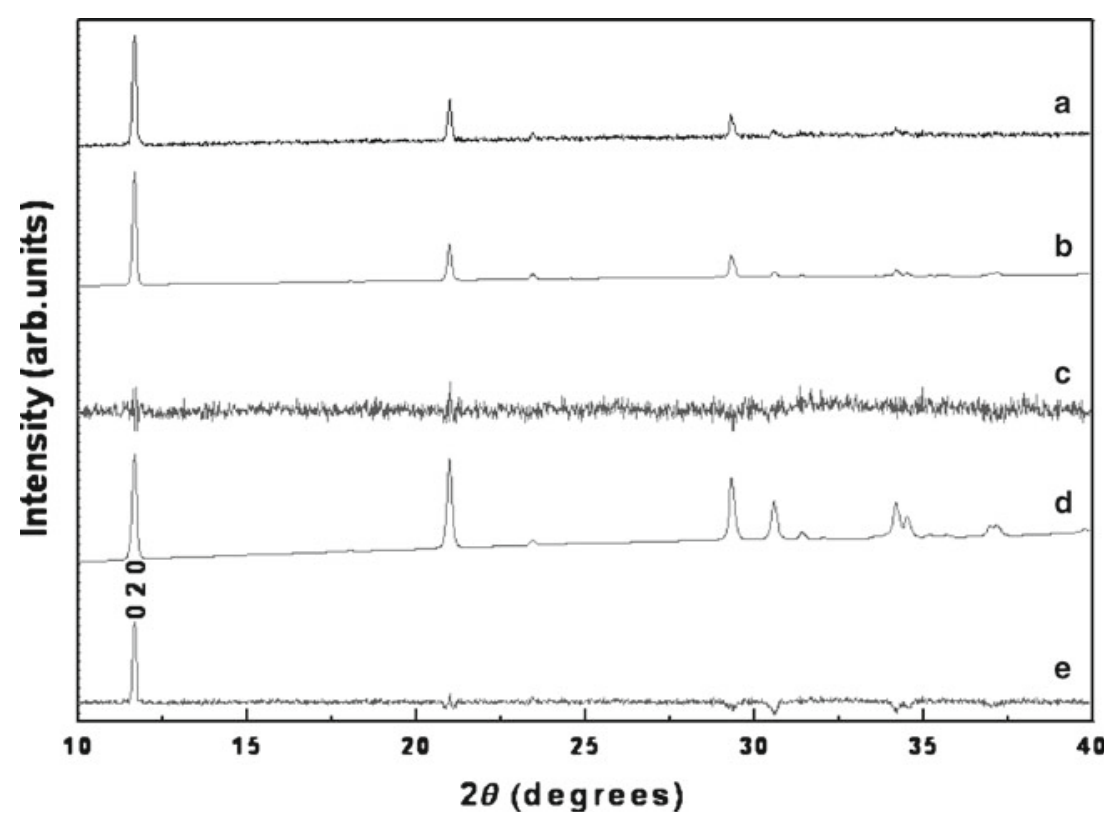

Figure 2. PXRD profile of (a) DCPD coating obtained at $8 \mathrm{~mA} \mathrm{~cm}^{-2}$ deposition current compared with (b) calculated XRD profile incorporating effect of orientation and (c) is corresponding difference profile. (d) and (e) are calculated XRD profile and difference profile, respectively obtained before incorporation of orientation effects.

intensities are generally due to oriented growth. The refinement was repeated by incorporating March function parameters to account for the preferred orientation along this direction (table 1). The resultant fit was satisfactory and the difference profile was a smooth function.

PXRD pattern of a $\mathrm{CaHPO}_{4} \cdot 2 \mathrm{H}_{2} \mathrm{O}$ coating obtained when the deposition current was $12 \mathrm{~mA} \mathrm{~cm}{ }^{-2}$ is shown in figure 3 .
In this pattern, the peak corresponding to the $12 \overline{1}$ reflection is the strongest of all the observed reflections. In this case, Rietveld fit of the observed profile shows residual intensity in the difference profile at $2 \theta$ value corresponding to the (12î) plane. After repeating the refinement with orientation parameters (see table 1), the difference profile was a smooth function. 
Morphologies of all the coatings were examined by scanning electron microscopy (SEM). SEM images of the 020 oriented coatings (figures $4 \mathrm{a}$ and $\mathrm{b}$ ) show laths having a length of several micrometers. Figure 4(c) shows structure of the DCPD which consists of bilayer arrangement of calcium, hydrogenphosphate and water molecules. The 020 plane ends with a layer of water molecules (Sainz-Diaz et al 2004). Consequently, the 020 plane is nonpolar. In general, nonpolar crystal planes have a low surface energy and crystal growth along the normal and does not lead to significant energy gains as bonding is weak. On the contrary, strong iono-covalent bonding leads to in-plane growth as accretion of atoms to the plane edges leads to large energy gains. The resultant crystallites are found to terminate at the 020 crystal planes leading to the lath-like morphology. Figure 4(d) is a schematic of one such lath.

The scanning electron microscopy images (figure 5) of the $12 \overline{1}$ oriented coating show platelet-like crystallites stacked one above the other. These stacks are inclined to the substrate surface. The stacks are oriented in different directions to yield clusters. These clusters are seen together with lath-like crystallites.

Table 1. March function parameters obtained from Rietveld fits of the observed PXRD profiles of DCPD coatings.

\begin{tabular}{lccc}
\hline \multirow{2}{*}{$\begin{array}{l}\text { Deposition current } \\
\left(\mathrm{mA} \mathrm{cm}^{-2}\right)\end{array}$} & Orientation & $G_{1}$ & $G_{2}$ \\
\hline 8 & 020 & 0.43 & 0.62 \\
12 & $12 \overline{1}$ & 0.50 & 0.73 \\
\hline
\end{tabular}

At high currents, the deposition process enters the regime of kinetic control, leading to the growth of planes other than the thermodynamically stable 020 plane. The value of the crystallographic angle, $\beta$, of DCPD is $116.43^{\circ}$ and is close to the hexagonal value of $120^{\circ}$. Consequently, a pseudohexagonal symmetry can be visualized in the DCPD crystal, bounded by the $\{h k 0\}$ planes $(h, k=0, \pm 1)$. Crystal growth in the $a-b$ plane of the pseudo-hexagonal lattice ( $a-c$ plane of the monoclinic crystal) leads to crystallites with a hexagonal platelet morphology. The $(12 \overline{1})_{m}$ ( $m$ : monoclinic) plane is inclined to the $[001]_{h}$ ( $h$ : pseudo-hexagonal) as shown in figure 5(c). When the platelets are inclined with respect to the substrate, the $[12 \overline{1}]$ is normal to the substrate, resulting in the $12 \overline{1}$ out of plane orientation for the coating (figure 5d). Further, the high rate of deposition also causes secondary nucleation generating stacks of crystallites.

\subsection{DCPD $\rightarrow$ HA transformation}

DCPD coatings were aged in alkali at different temperatures for different lengths of time to transform them into the hydroxyapatite phase. The reaction is

$$
\begin{aligned}
5\left(\mathrm{CaHPO}_{4} \cdot 2 \mathrm{H}_{2} \mathrm{O}\right)+6 \mathrm{OH}^{-} \rightarrow & \mathrm{Ca}_{5}\left(\mathrm{PO}_{4}\right)_{3}(\mathrm{OH}) \\
& +2 \mathrm{PO}_{4}^{3-}+15 \mathrm{H}_{2} \mathrm{O} .
\end{aligned}
$$

However, the transformation kinetics were different in differently-oriented coatings. The coating with 020 orientation was comparatively more stable and resistant to ageing. A complete transformation could not be affected below $85^{\circ} \mathrm{C}$. At lower temperatures $\left(60^{\circ} \mathrm{C}\right)$ and at various ageing times

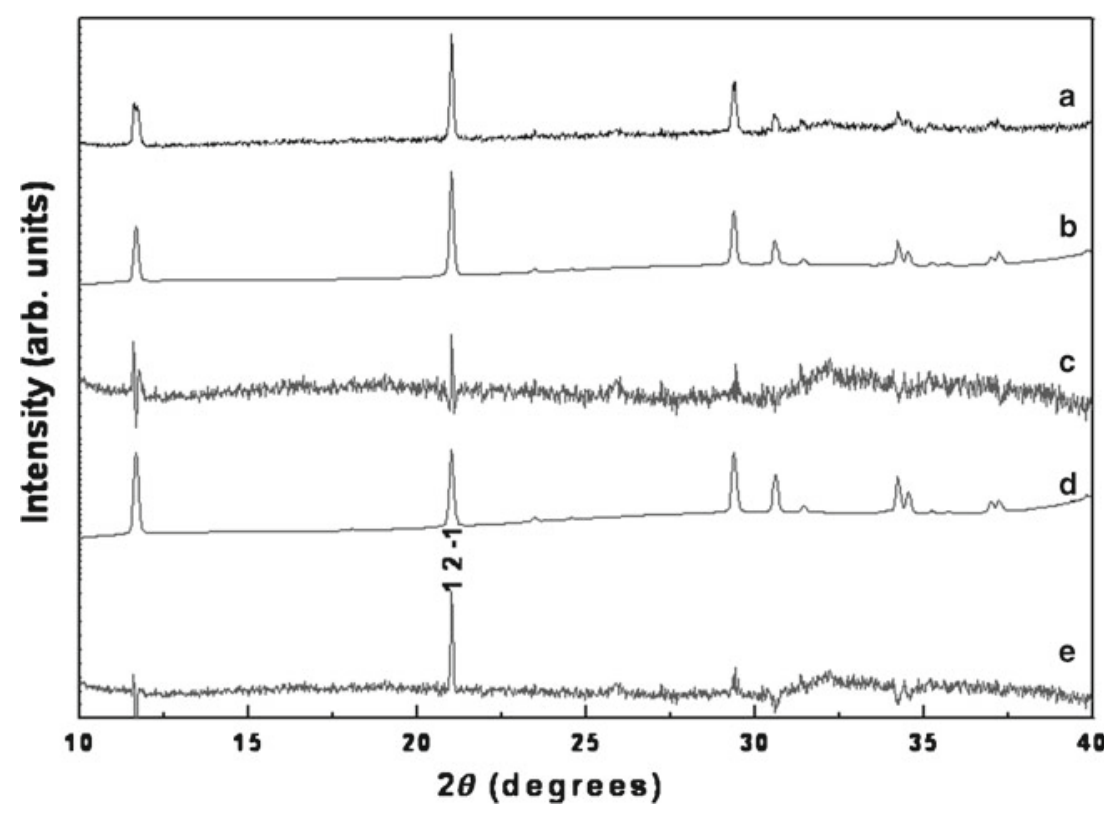

Figure 3. PXRD profile of (a) DCPD coating obtained at $12 \mathrm{~mA} \mathrm{~cm}^{-2}$ deposition current compared with (b) calculated XRD profile incorporating effect of orientation and (c) is corresponding difference profile. (d) and (e) are calculated XRD profile and difference profile, respectively obtained before incorporation of orientation effects. 


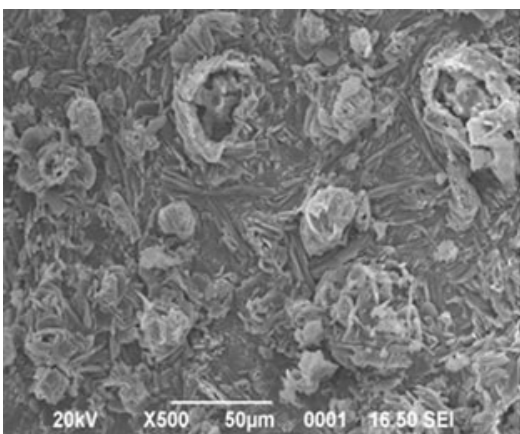

a

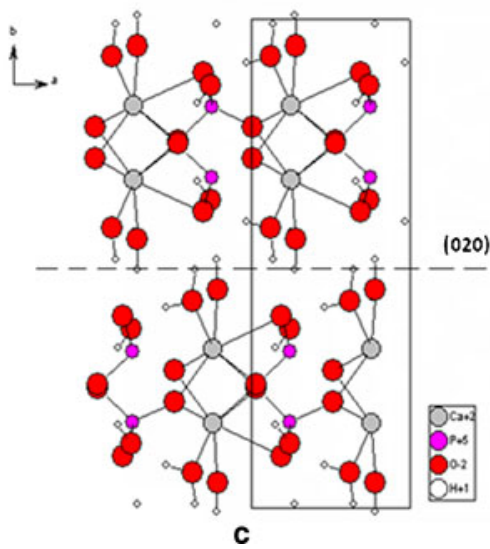

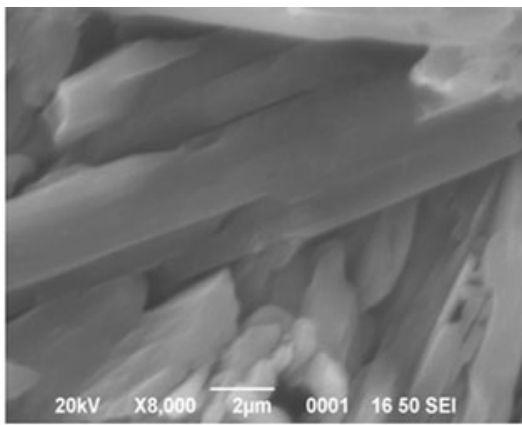

b

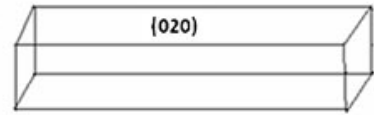

d

Figure 4. SEM images of 020 oriented DCPD coatings obtained at (a) low and (b) high magnifications, respectively. (c) Crystal structure of DCPD and (d) schematic of a lath-like crystallite facetted by 020 crystal plane.

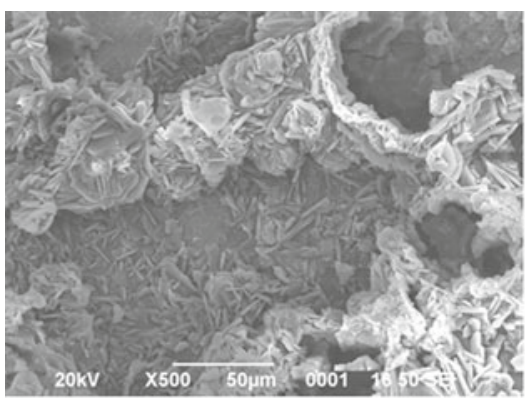

a

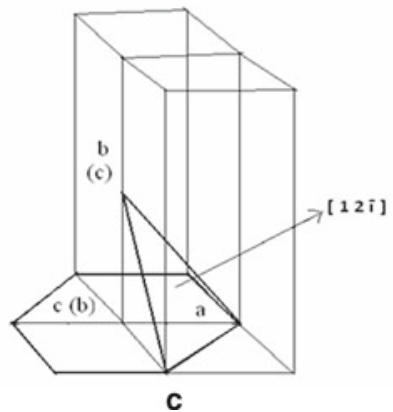

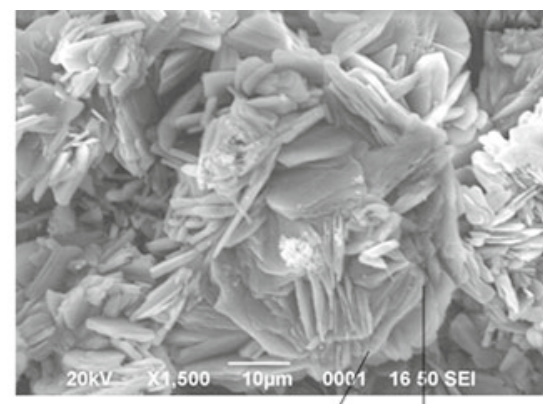

b

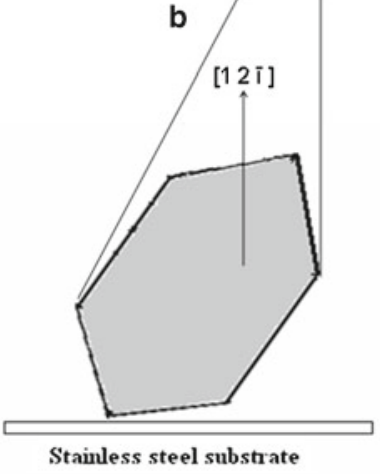

d

Figure 5. SEM images of $12 \overline{1}$ oriented DCPD coatings obtained at (a) low and (b) high magnifications, respectively. (c) Schematic of unit cell of DCPD showing the $12 \overline{1}$ crystal plane. Axes are labelled with respect to monoclinic symmetry. Labels in parentheses correspond to pseudo-hexagonal symmetry and (d) Pseudo-hexagonal platelets tilted to produce a $12 \overline{1}$ out of plane orientation. 

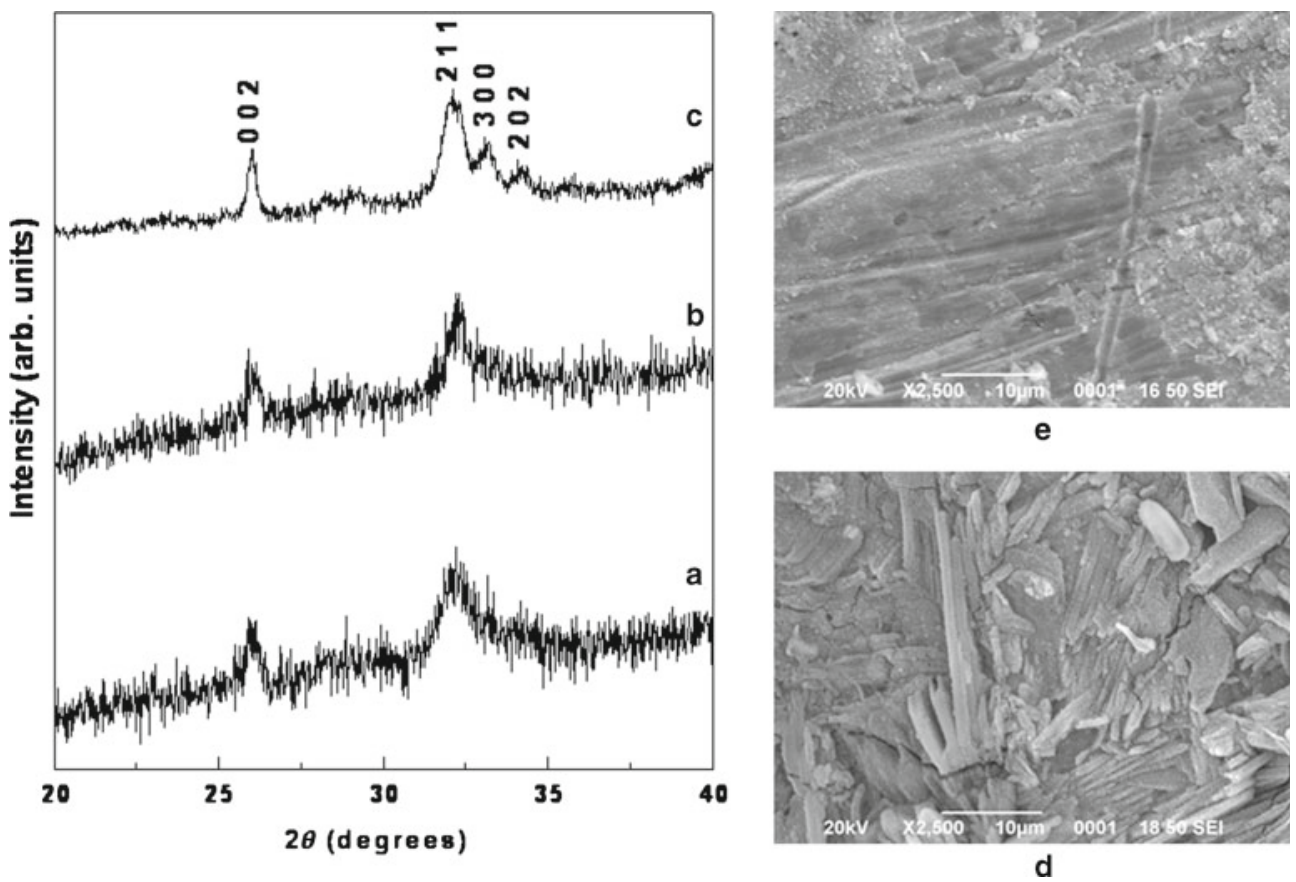

Figure 6. PXRD profiles and SEM images of hydroxyapatite coatings obtained from 020 oriented DCPD coatings aged at $(\mathbf{a}, \mathbf{d}) 60^{\circ} \mathrm{C}$ for $6 \mathrm{~h}$, (b) $60^{\circ} \mathrm{C}$ for $18 \mathrm{~h}$ and $(\mathbf{c}, \mathbf{e}) 85^{\circ} \mathrm{C}$ for $6 \mathrm{~h}$.
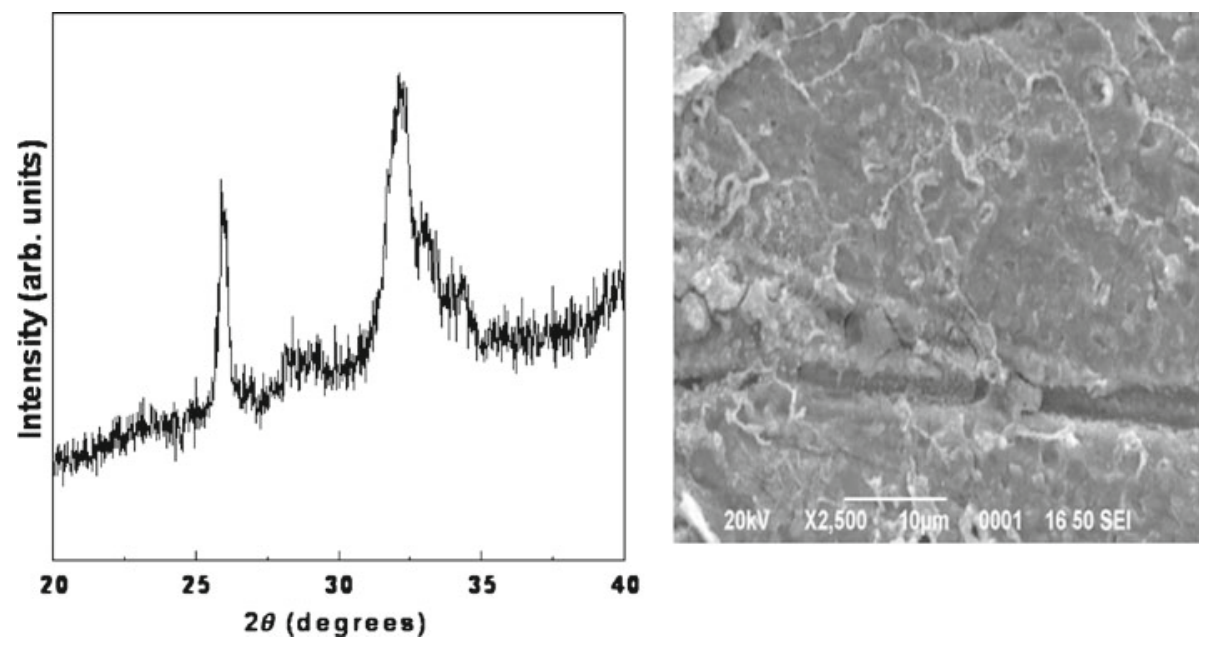

Figure 7. PXRD profile and SEM image of a hydroxyapatite coating obtained from a $12 \overline{1}$ oriented DCPD coating aged at $60{ }^{\circ} \mathrm{C}$ for $6 \mathrm{~h}$.

(6-18 h), the Bragg reflections of the DCPD phase are absent, but reflections due to HA are not well defined (figures $6 \mathrm{a}, \mathrm{b}$ ). At this stage, morphology of the coating is the same as that of the precursor DCPD phase and laths similar to those in figure 4 are seen (figure $6 \mathrm{~d}$ ). The sum total of the evidence points to an incomplete transformation. At $85^{\circ} \mathrm{C}$, the transformation is complete even at short-ageing times $(6 \mathrm{~h})$ and the corresponding PXRD pattern (figure $6 \mathrm{c}$ ) is indexed to hexagonal HAP ( $a=9.352 \AA ; c=6.882 \AA)$. The morphology has completely changed. A continuous covering of the substrate is observed; such a morphology is obtained by the merging of parallely-oriented laths across their edges.
Residual striations can still be seen in certain regions of the coatings (figure 6e).

The formation of the hydroxyapatite phase could also be seen in the IR spectra (figure 1b), which shows the disappearance of the vibrations due to hydrogenphosphate and the appearance of a single broad vibration due to the tetrahedral-orthophosphate ion. The $\mathrm{OH}$ stretching region also shows the changes expected of this transformation.

DCPD coating with $12 \overline{1}$ orientation undergoes a facile transformation to $\mathrm{HA}$ at $60{ }^{\circ} \mathrm{C}$ (duration, $6 \mathrm{~h}$ ) itself (figure 7). The X-ray pattern shows all the reflections expected of hydroxyapatite and in this case the platelets of the precursor 
coating are seen to merge at their edges to create a mosaic pattern that covers the substrate surface completely.

\section{Conclusions}

In conclusion, we report the one-step electrodeposition of dicalcium phosphate dihydrate (DCPD) coatings on stainless steel substrates by cathodic electrogeneration of base. The coatings grow in two preferred directions - 020 and $12 \overline{1}$ — depending upon the deposition current. The biochemical importance of DCPD arises on account of its ability to transform into hydroxyapatite, the inorganic component of bones. DCPD coating oriented along $12 \overline{1}$ transforms to hydroxyapatite in a very facile manner at a lower temperature $\left(60^{\circ} \mathrm{C}\right)$ and shorter ageing time $(<6 \mathrm{~h})$ compared to the coating oriented along 020 . This observation is in keeping with the lower surface energy and higher thermodynamic stability of the 020 crystal plane of DCPD. The low surface energy of the 020 plane is on account of its nonpolar nature which inhibits interaction with the polar solvent.

\section{Acknowledgements}

One of the authors (BEP) thanks the Council of Scientific and Industrial Research, Government of India, for the award of a Senior Research Fellowship. (PVK) is a recipient of the Ramanna Fellowship of the Department of Science and Technology, New Delhi.

\section{References}

Chow L C and Brown W E 1982 Proc. of third annual conf. on foods, nutrition and dental health 2217

Constantz B R et al 1998 J. Biomed. Mater. Res. 43451
Corrigan D A and Bendert R M 1989 J. Electrochem. Soc. 136723

Curry N A and Jones D W 1971 J. Chem. Soc. (A) 3725

Dobos D 1975 Electrochemical data (Amsterdam: Elsevier Scientific)

Dorozhkin S V 2007 J. Mater. Sci. 421061

Drissens F C M, Boltong M G, Bermudez O, Planell J A, Ginebra M P and Fernandez E 1994 J. Mater. Sci. Mater. Med. 5164

Hesse A and Heimabch D 1999 World J. Urol. 17308

Huaxia J I, Ponton C B and Marquis P M 1992 J. Mater. Sci. Mater. Med. 3283

Johnsson M S and Nancollas G H 1992 Crit. Rev. Oral. Biol. Med. 361

Lecomte J, Boulle A and Lang-Dupont M 1955 Comp. Rend. 241 1927

Legeros R Z 1991 Calcium phosphates in oral biology and medicine, (ed.) H M Myers (Basel: Karger) Chap. 6, p. 154

Legeros R Z 1994 in Hydroxyapatite and related materials (eds) P W Brown and B Constantz (Boca Raton: CRC Press) p. 3

Morancho R, Ghommidh J, Constant G, Moyen B, Comtet J J, Santini R and Buttazzoni B 1983 Mater. Sci. Monogr. 171983

Mostashari S M, Haddadi H and Hashempoor Z 2006 Asian J. Chem. 182388

Petrov I, Soptrajanov B, Fuson N and Lawson J R 1967 Spectrochim. Acta 23A 2637

Raemdonk W V, Ducheyne P and Meester P D 1984 J. Am. Ceram. Soc. 67381

Rukenstein E, Gourisankar S and Baier R E 1983 J. Colloid. Interf. Sci. 96245

Sainz-Diaz C I, Villacampa A and Otalor F 2004 Am. Miner. 89307

Spoto G, Ciliberto E and Allen G C 1994 J. Mater. Chem. 41849

Therese G H A, Kamath P V and Subbanna G N 1998 J. Mater. Chem. 8405

Tlili M M, Benomar M, Gabbrielli C, Perrot H and Tribollet B 2003 J. Electrochem. Soc. 150 C765

Yamamoto H, Niwa S, Hori M, Hattori T, Sawai K, Akoi S, Hirano M and Takeuchi H 1998 Biomaterials 191587

Yamashita K and Kanazawa T 1989 in Inorganic phosphate materials (ed.) T Kanazawa (Amsterdam: Elsevier)

Zhitomirsky I, Gal-Or L, Khon A and Hennicke W H 1995 J. Mater. Sci. 305307 